\title{
AVALIAÇÃO MICROBIOLÓGICA DE LANCHES NATURAIS COMERCIALIZADOS EM CANTINAS DE UMA UNIVERSIDADE DO MUNICÍPIO DE PRESIDENTE PRUDENTE - SP
}

Telma Reginato Martins; Angélica Viana; Jéssica Espíndola da Costa.

Universidade do Oeste Paulista - UNOESTE, Curso de Nutrição, Presidente Prudente - SP. E-mail: telmaneves@unoeste.br

\section{RESUMO}

O objetivo desta pesquisa foi avaliar a qualidade sanitária de lanches naturais comercializados em cantinas de uma universidade de Presidente Prudente - SP. Foram analisados lanches naturais de 7 estabelecimentos, durante 3 semanas consecutivas, totalizando 21 amostras. Em cada analise foi realizada a contagem de bactérias mesófilas aeróbias, bolores e leveduras, estafilococos coagulase positiva, coliformes totais e termotolerantes e Salmonella spp (presença ou ausência). Quatro estabelecimentos apresentaram Salmonella spp. em 25 gramas de lanche, três estabelecimentos com contagens elevadas de bolores e leveduras e todos apresentaram contagens elevadas de mesófilos aeróbios. Cinco estabelecimentos apresentaram número mais provável de coliformes termotolerantes acima do máximo estabelecido na legislação, sendo que um dos estabelecimentos apresentou confirmação de $E$. coli. Conclui-se que estes produtos carecem de um cuidado especial quanto à forma de manipulação desses alimentos, sendo necessária a utilização de boas práticas de higiene na manipulação e armazenamento desses produtos.

Palavras-chave: lanches naturais, contaminação, doenças veiculadas por alimentos, microrganismo, segurança alimentar.

\section{MICROBIOLOGICAL ANALYSIS OF NATURAL SNACKS COMMERCIALIZED IN CAFETERIAS AT A UNIVERSITY IN Presidente Prudente - SP}

\begin{abstract}
The objective of this research was to evaluate the sanitary quality natural snacks sold in cafeterias of Presidente Prudente University - SP. They were analyzed natural snacks 7 establishments for 3 consecutive weeks, totaling 21 samples. In each analysis was performed to count mesophilic aerobic bacteria, yeasts and molds, coagulase-positive staphylococci, total and fecal coliforms and Salmonella spp (presence or absence). Four establishments showed Salmonella spp. 25 grams of snack three establishments with high counts of yeasts and molds and all showed high counts of aerobic mesophilic. Five establishments were more likely number of fecal coliforms above the maximum established in the legislation, and one of the establishments had confirmation of $E$. coli. It is concluded that these products require special care as to handling these foods, being necessary to use good hygiene practices in handling and storage of these products.
\end{abstract}

Keywords: natural snacks, contamination, foodborne illnesses, microorganism, food security. 


\section{INTRODUÇÃO}

Atualmente no Brasil, estima-se um grande aumento e desenvolvimento dos estabelecimentos que produzem alimentos para consumo imediato, como "fast food", lanchonetes e cantinas ${ }^{1}$. Nas universidades é fácil observar essa mudança no consumo alimentar e a grande procura por esses tipos de estabelecimentos, onde estudantes apressados alimentam-se de refeições práticas compradas em lanchonetes ${ }^{2}$. Com intuito de agregar comida rápida e saudável ao mesmo tempo, a procura por lanches do tipo natural vem aumentando cada vez mais, pois os estudantes buscam associar qualidade da alimentação sem despender tempo para alimentar-se ${ }^{3}$.

Segundo Souza et al. (2009) ${ }^{4}$, essa alimentação não representa apenas um déficit nutricional, mas um perigo de contaminação, pois esses estabelecimentos nem sempre apresentam condições necessárias e exigidas pela Agência Nacional de Vigilância Sanitária $(\text { ANVISA })^{5}$, seja pela infraestrutura do local ou pela incapacidade técnica dos manipuladores em conservar os alimentos de forma correta. As hortaliças, em especial, as consumidas cruas, necessitam ser puras e saudáveis, sendo estas, comumente usadas na formulação de lanches naturais. No entanto, possibilitam ocorrência de enfermidades intestinais, uma vez que helmintos, protozoários e outros patógenos podem estar presentes nessas verduras, que são frequentemente adubadas e/ou irrigadas com água contaminada por dejetos fecais. As doenças transmitidas por alimentos são, predominantemente, resultantes do ciclo de contaminação fecal/oral e seu controle deve receber atenção cada vez maior em nosso meio ${ }^{6}$.

Segundo Faria et al (2012) ${ }^{7}$, as doenças alimentares geralmente são de origem microbiológica; os patógenos mais comuns encontrados são Salmonella ssp, Staphylococcus aureus, Bacillus cereus e Clostridium perfringens. Os sintomas podem variar desde um mal estar, cólicas, vômitos e febre ou até mesmo à óbito.

Considerando-se que, durante o pré preparo e montagem, estes lanches podem sofrer manuseio excessivo sob condições higiênicas precárias, armazenamento inadequado e deficiente, além do preparo por pessoas sem capacitação e conhecimentos para a manipulação correta, ficam evidentes os riscos para a saúde dos consumidores ${ }^{8}$. Esse manuseio excessivo durante o fracionamento, a lavagem incorreta das mãos e as condições de aeração e embalagem aumentam os riscos da presença de microrganismos patogênicos transmissores de doenças ao consumidor ${ }^{10}$. Além disto, a matéria prima para a confecção dos lanches pode vir contaminada por microrganismos procedentes do campo.

Assim, é importante a adoção de medidas que propiciem uma melhoria da qualidade desses produtos. Entre os procedimentos de higienização mais conhecidos ressalta-se a lavagem doméstica de hortaliças e a desinfecção das mesmas ${ }^{11}$.

A contaminação dos alimentos pode ser evitada se os alimentos forem manipulados conforme o estipulado pela cartilha de Boas Práticas para Serviços de Alimentação, que são baseadas na legislação sanitária federal cujo órgão responsável é a ANVISA (ANVISA, 2004) ${ }^{5}$.

Considerando-se que os lanches naturais, por serem constituídos de alimentos in natura, possuem uma maior probabilidade de sofrerem contaminação microbiológica quando não passam pelos processos de desinfecção, manipulação e conservação corretos de acordo com a legislação, e podem representar riscos à saúde dos universitários, este estudo teve como objetivo analisar amostras de lanches naturais comercializados em cantinas de dois campi de uma universidade localizada na cidade de Presidente Prudente - SP.

\section{MÉTODOS}

Foram escolhidas para análise cantinas localizadas nos 2 campi da universidade, utilizando como critério de inclusão todas as que comercializavam lanche natural de frango. 
Todas as amostras foram compradas em triplicata como se apresentavam nos estabelecimentos e transportadas em caixa isotérmica até o Laboratório de Análise de Alimentos da Universidade do Oeste Paulista (UNOESTE), onde foram realizadas as análises microbiológicas.

No total foram colhidas 21 amostras de lanche natural de frango; a periodicidade da coleta foi de uma amostra a cada sete dias de 7 estabelecimentos durante três semanas consecutivas. A partir de $25 \mathrm{~g}$ de cada amostra homogeneizada com $225 \mathrm{~mL}$ de água peptonada 0,1\% (diluição 1:10) foram realizadas diluições decimais seriadas para determinação do Número Mais Provável (NMP) de bactérias por grama de alimento de coliformes totais e coliformes termotolerantes e Escherichia coli, para verificação e identificação de Staphylococcus coagulase positiva, contagem de bolores e leveduras e mesófilos aeróbios, bem como para a detecção de Salmonella spp. de acordo com metodologia proposta por Silva, Silveira e Junqueira (2010) ${ }^{15}$.

Os dados foram tabulados e os resultados foram representados em tabelas de contingência para comparação com a legislação em vigor.

\section{RESULTADOS}

Todas as amostras de lanche natural de frango foram pesadas e seus ingredientes foram descritos no Quadro 1.

Quadro 01. Descrição das amostras de lanche natural de frango das cantinas de dois campi de uma universidade de Presidente Prudente - SP.

\begin{tabular}{|c|c|c|}
\hline $\begin{array}{c}\text { Lanche natural } \\
\text { de frango }\end{array}$ & Descrição & Massa (g) \\
\hline A & $\begin{array}{r}\text { Pão sírio, frango desfiado, alface, tomate em rodela, } \\
\text { cenoura ralada, queijo mussarela e maionese }\end{array}$ & 247,6 \\
\hline B & Pão sírio, patê de frango, alface e cenoura & 192,6 \\
\hline C & Pão integral, frango desfiado, maionese, alface e tomate & 184,1 \\
\hline D & Pão de leite, frango desfiado, alface, cenoura, maionese, \\
cheiro verde & 136,3 \\
\hline E & Pão sírio, frango desfiado, alface, cenoura, maionese, \\
azeitona e milho & 144,9 \\
\hline F & Pão de forma integral, frango desfiado, alface, cenoura, \\
beterraba, cheiro verde & 130,1 \\
\hline G & Pão sírio, frango desfiado, alface, cenoura e maionese & 197,9 \\
\hline
\end{tabular}

A massa média dos lanches foi de 176,2 g $\pm 42,0$ (variando de 130,1 até 247,6 ). Os ingredientes mais prevalentes foram: maionese, frango desfiado, alface, cenoura e pão sírio. Todos os lanches estavam livres de qualquer tipo de contaminação física. As embalagens estavam todas íntegras e eram basicamente constituídas de filme plástico e algumas possuíam bandejas de isopor descartável. Nos estabelecimentos $\mathrm{D}$ e $\mathrm{E}$ os lanches estavam à temperatura ambiente expostos sobre o balcão, o que pode contribuir para um crescimento mais rápido dos microrganismos.

Os resultados obtidos nas análises microbiológicas dos lanches naturais, nas 3 coletas consecutivas $\left(1^{\mathrm{a}}, 2^{\mathrm{a}}\right.$ e $\left.3^{\mathrm{a}}\right)$ estão descritos nas tabelas $1,2,3,4$ e 5 que se seguem: 
Tabela 01.S. aureus em amostras de lanche natural de frango das cantinas de dois campi de uma universidade do município de Presidente Prudente - SP

\begin{tabular}{cccc}
\hline & \multicolumn{3}{c}{ S. aureus (UFC/g) } \\
Estabelecimento & $\mathbf{1}^{\text {a }}$ & $\mathbf{2}^{\mathbf{a}}$ & $\mathbf{3}^{\mathbf{a}}$ \\
\hline $\mathbf{A}$ & $<10$ est & $<10$ est & $<10$ est \\
$\mathbf{B}$ & $7,6 \times 10^{3}$ & $<10$ est & $<10$ est \\
$\mathbf{C}$ & $<10$ est & $<10$ est & $<10$ est \\
$\mathbf{D}$ & $<10$ est & incontável & incontável \\
E & $<10$ est & $<10$ est & $<10$ est \\
$\mathbf{F}$ & $<10$ est & $<10$ est & $<10$ est \\
$\mathbf{G}$ & $<10$ est & $<10$ est & $<10$ est \\
\hline
\end{tabular}

Tabela 02. Bolores e Leveduras em amostras de lanche natural de frango das cantinas de dois campi de uma universidade do município de Presidente Prudente - SP

\begin{tabular}{cccc}
\hline & \multicolumn{3}{c}{ Bolores e Leveduras (UFC/g) } \\
\cline { 2 - 4 } Estabelecimento & $\mathbf{1}^{\mathbf{a}}$ & $\mathbf{2}^{\mathbf{a}}$ & $\mathbf{3}^{\mathbf{a}}$ \\
\hline A & $>6,5 \times 10^{5}(\mathrm{est})$ & $>6,5 \times 10^{5}$ (est) & $>6,5 \times 10^{5}$ (est) \\
B & $7,9 \times 10^{3}$ & $2,0 \times 10^{3}$ & $1,2 \times 10^{3}$ \\
C & $8 \times 10^{2}$ & $7,5 \times 10^{2}$ & $71 \times 10^{2}$ \\
D & $2 \times 10^{2}$ & $47 \times 10^{2}$ & $>6,5 \times 10^{5}$ (est) \\
E & $67,5 \times 10^{3}$ & $>6,5 \times 10^{5}$ (est) & $81 \times 10^{2}$ \\
F & $74 \times 10^{2}$ & $8 \times 10^{2}$ & $7,5 \times 10^{4}$ \\
G & $27 \times 10^{4}$ & $6,5 \times 10^{2}$ & $10,5 \times 10^{2}$ \\
\hline
\end{tabular}

Tabela 03. Mesófilos aeróbios em amostras de lanche natural de frango das cantinas de dois campi de uma universidade do município de Presidente Prudente - SP

\begin{tabular}{cccc}
\hline & \multicolumn{3}{c}{ Mesófilos aeróbios (UFC/g) } \\
Estabelecimento & $\mathbf{1}^{\mathbf{a}}$ & $\mathbf{2}^{\mathbf{a}}$ & $\mathbf{3}^{\mathbf{a}}$ \\
\hline A & $6,4 \times 10^{3}$ & $3,2 \times 10^{3}$ & $3,1 \times 10^{3}$ \\
B & $5,5 \times 10^{4}$ & $1,2 \times 10^{4}$ & $8,0 \times 10^{3}$ \\
C & $1,7 \times 10^{4}$ & $1,8 \times 10^{3}$ & $>6,5 \times 10^{5}$ (est) \\
D & $7,2 \times 10^{3}$ & $>6,5 \times 10^{5}$ (est) & $>6,5 \times 10^{5}$ (est) \\
E & $7,0 \times 10^{4}$ & $>6,5 \times 10^{5}$ (est) & $1,1 \times 10^{6}$ \\
F & $3,6 \times 10^{5}$ & $>6,5 \times 10^{5}$ (est) & $3,1 \times 10^{5}$ \\
G & $>6,5 \times 10^{5}$ (est) & $7,2 \times 10^{3}$ & $1,8 \times 10^{4}$ \\
\hline
\end{tabular}


Tabela 04. Salmonella spp. em amostras de lanche natural de frango das cantinas de dois campi de uma universidade do município de Presidente Prudente - SP

\begin{tabular}{cccc}
\hline & \multicolumn{3}{c}{ Salmonella spp. (em 25g) } \\
Estabelecimento & $\mathbf{1}^{\mathbf{a}}$ & $\mathbf{2}^{\mathbf{a}}$ & $\mathbf{3}^{\mathbf{a}}$ \\
\hline A & Ausência & Ausência & Ausência \\
B & Ausência & Presença & Presença \\
C & Ausência & Ausência & Ausência \\
D & Ausência & Ausência & Ausência \\
E & Ausência & Ausência & Presença \\
F & Ausência & Presença & Ausência \\
G & Ausência & Presença & Ausência \\
\hline
\end{tabular}

Tabela 05. Coliformes Totais e Termotolerantes em amostras de lanche natural de frango das cantinas de dois campi de uma universidade do município de Presidente Prudente - SP

\begin{tabular}{ccccccc} 
& \multicolumn{3}{c}{ Coliformes Totais } & \multicolumn{3}{c}{ Coliformes Termotolerantes } \\
Estabelecimento & $\mathbf{1}^{\mathbf{a}}$ & $\mathbf{2}^{\mathbf{a}} \mathbf{\mathbf { a }}$ & $\mathbf{3}^{\mathbf{a}}$ & $\mathbf{1}^{\mathbf{a}}$ & $\mathbf{2}^{\mathbf{a}}$ & $\mathbf{3}^{\mathbf{a}}$ \\
\cline { 2 - 7 } A & $2,4 \times 10^{2}$ & $<3$ & 23 & $2,4 \times 10^{2}$ & $<3$ & 43 \\
B & $\geq 2,4 \times 10^{3}$ & $<3$ & $2,4 \times 10^{2}$ & $\geq 2,4 \times 10^{3}$ & $<3$ & $2,4 \times 10^{2}$ \\
C & 93 & $<3$ & 9 & 93 & $<3$ & 9 \\
D & $\geq 2,4 \times 10^{3}$ & 15 & $\geq 2,4 \times 10^{3}$ & $<3$ & $\geq 1,1 \times 10^{3}$ & $\geq 2,4 \times 10^{3 *}$ \\
E & 20 & $2,4 \times 10^{2}$ & $2,1 \times 10^{2}$ & 28 & $2,4 \times 10^{2}$ & 75 \\
F & $\geq 1,1 \times 10^{3}$ & $2,4 \times 10^{2}$ & 9 & $<3$ & $2,4 \times 10^{2}$ & 9 \\
G & $\geq 2,4 \times 10^{3}$ & 43 & 21 & $<3$ & 43 & 28
\end{tabular}

* confirmação de presença de E. coli

\section{DISCUSSÃO E CONCLUSÃO}

Das 21 amostras analisadas 2 foram positivas (B e D) para Staphylococcus aureus (Tabela 1), apresentando contagens elevadas para o padrão estabelecido de $5 \times 10^{3} \mathrm{UFC} / \mathrm{g}$ pela RDC no 12 de 02/01/2001 16. A presença de Estafilococos coagulase positiva em alimentos é preocupante, principalmente por estar relacionada com surtos de intoxicação alimentar e com o controle higiênico-sanitário da manipulação dos alimentos ${ }^{14}$.

As amostras A, D e E apresentaram contagens de bolores e leveduras (Tabela 2) muito elevadas, indicando condições inadequadas de processamento e armazenamento. De acordo com Silva et al $(2010)^{15}$, a detecção destes microrganismos nos alimentos em índice elevado indica falhas no processamento e até mesmo na estocagem destes alimentos e nas condições higiênicas deficientes de equipamentos.

Podemos observar na Tabela 3, de forma geral, uma contagem elevada deste grupo de microrganismos. A presença de Mesófilos Aeróbios é considerada um dos indicadores microbiológicos de qualidade mais utilizados, demonstrando se o processo de limpeza, desinfecção, controle de temperatura e armazenamento foram realizados de forma inadequada.

A Tabela 4 demonstra detecção de Salmonela ssp. em $25 \mathrm{~g}$ de lanches naturais. Apresentaram presença de Salmonella ssp., a amostra B na segunda e na terceira semana de 
coleta, E na terceira coleta, F e G na segunda coleta. A detecção de Salmonela ssp. nas amostras, demonstra que os lanches naturais preparados nestes estabelecimentos estão impróprios para o consumo, podendo acarretar problemas na saúde do consumidor ${ }^{18}$, sendo um dos principais agentes causadores de DVAs de todo o mundo.

A Tabela 5 mostra a determinação de coliformes totais e termotolerantes em lanches do tipo natural de frango. Algumas amostras apresentaram uma quantidade muito elevada de coliformes fecais de acordo com o estabelecido pela RDC no 12/2001 da Agência Nacional de Vigilância Sanitária ${ }^{15}$, cujo limite de quantificação máximo é de $10^{2} \mathrm{NMP} / \mathrm{g}$ de coliformes a $45^{\circ} \mathrm{C}$. Os estabelecimentos que apresentaram todas as amostras adequadas foram apenas $\mathrm{C}$ e $\mathrm{G}$. Houve confirmação de contaminação por E.coli apenas na amostra $D$ em sua terceira semana de coleta. A E.coli encontrada na amostra indica que houve contaminação de origem fecal e que o produto avaliado está fora do padrão exigido para consumo humano, de acordo com a RDC no 12 de 02 de janeiro de $2001^{15}$.

A resolução RDC №. 218, DE 29 DE JULHO DE $2005^{18}$ diz que os manipuladores devem lavar cuidadosamente as mãos antes e depois de manipular alimentos, após qualquer interrupção da atividade, tocar materiais contaminados, e principalmente depois de usar o sanitário. Não se deve fumar, falar desnecessariamente, cantar, assobiar, espirrar, cuspir, tossir, comer ou praticar outros atos que possam contaminar o alimento durante o preparo. Utilizar instrumentos e ou utensílios limpos ao realizar as operações de corte, fatiamento, dentre outras. Esses cuidados reduzem significativamente o risco de contaminações que tenham como origem os seus manipuladores.

De todas as amostras analisadas, 4 estabelecimentos apresentaram presença de Salmonella spp. em 25 gramas do alimento, 3 estabelecimentos com contagens elevadas de bolores e leveduras e todos os estabelecimentos com contagens elevadas de mesófilos aeróbios. Além disto, 7 estabelecimentos apresentaram número mais provável de coliformes termotolerantes acima do máximo estabelecido na legislação, sendo que um dos estabelecimentos apresentou confirmação de E. coli, microrganismo utilizado como indicador de contaminação fecal.

Diante destes resultados, pode-se concluir que os Lanches Naturais de Frango comercializados em uma Universidade do município de Presidente Prudente - SP merecem um cuidado especial, com boas praticas de manipulação, no que condiz com as práticas de higiene e desinfecção praticadas pelos manipuladores, assim como as formas de armazenamento do produto.

\section{AGRADECIMENTOS E CONFLITO DE INTERESSE}

Agradecemos o apoio financeiro do projeto concedido pela Unoeste por meio do projeto PEIC. Os autores declaram não haver qualquer potencial conflito de interesse que possa interferir na imparcialidade deste trabalho científico.

\section{REFERÊNCIAS}

SIQUEIRA ACP, COSTA AKO. Condições higiênico-sanitárias das cantinas de uma universidade pública em Fortaleza. Segurança Alim. e Nutr., Campinas, 2013 20(2):275-289.

LOPES FNO, MADOKORO RY, MARTINS VF. Análise da Conservação de Alimentos á Venda em Lanchonetes da UNICAMP. Revista Ciências do Ambiente. Junho, 2010 Volume 6, Número 1: 115. 
NEVES AL, SILVA DMA, RIBEIRO JS. Plano de Negócios: Estudo da Viabilidade de Implementação da Rede de Restaurantes Subway na Cidade de Presidente Prudente - SP. 2008, 1- 100.

SOUZA CH, SATHLER J, JORGE MN, HORST RFML. Avaliação das condições higiênico sanitárias em uma unidade de alimentação e nutrição hoteleira, na cidade de Timóteo - MG. NUTRIR GERAIS - Revista Digital de Nutrição, Ipatinga, v. 3, n. 4, p. 312- 329, 2009.

ANVISA. Cartilha sobre Boas Práticas para Serviços de Alimentação. Resolução-RDC no 216/2004. www.anvisa.gov.br.

MESQUITA VCC, SERRA CMB, BASTOS OMP. Contaminação por enteroparasitas em hortaliças comercializadas nas cidades de Niterói e Rio de Janeiro, Brasil. Revista da Sociedade Brasileira de Medicina Tropical, Rio de Janeiro, v. 34, n. 4, p. 189-194, 1999. Disponível em: <http://www.scielo.br/p df/rsbmt/v32n4/0814.pdf>. Acesso em 23 de out. de 2014

FARIA T, PAULA RAO, GERMANO JL, OLIVER JC. Qualidade microbiológica da água de consumo humano e dos alimentos comercializados em lanchonete universitária. Revista da Universidade Vale do Rio Verde, Três Corações, v. 10, n. 2, p. 360-369, ago./dez. 2012.

FANTUZZI E, PUSCHMANN R, VANETTI MCD. Microbiota contaminante em repolho minimamente processado. Rev. Ciên. Tec. de Alimentos, v.24, p. 207-211, 2004. https://doi.org/10.1590/S0101-20612004000200008.

PAULA NRF, BOAS EVBV, RODRIGUES LJ, CARVALHO RA, PICCOLI H. Qualidade de produtos minimamente processados e comercializados em gôndolas de supermercados nas cidades de Lavras - MG, Brasília - DF e São Paulo - SP. Ciênc Agrotec. 2005;33(1):219-27. https://doi.org/10.1590/S1413-70542009000100031.

COELHO LPS, OLIVEIRA SM, MILMAN MHA, KARASAWA KA, SANTOS RP. Detecção de formas transmissíveis de enteroparasitas na água e nas hortaliças consumidas em comunidades escolares de Sorocaba, São Paulo, Brasil. Rev. Soc. Bras. Med. Trop., Sorocaba, v. 34, n. 5, p. 479-482, 2001.

FONTANA N. Atividade antimicrobiana de desinfetantes utilizados na sanitização de alface. Trabalho de Conclusão de Curso (Graduação em bacharelado em nutrição) - Centro Universitário Franciscano, 2006.

PAULA P, RODRIGUES PSS, TÓRTORA JCO, UCHÔA CMA, FARAGE S. Contaminação microbiológica e parasitológica em alfaces (Lactuca sativa) de restaurantes self-service, de Niterói, RJ. Rev. Soc. Bras. Med. Trop. vol.36 no.4 Uberaba July/Aug. 2003.

SILVA N, JUNQUEIRA VCA, SILVEIRA NFA. Manual de métodos de análise microbiológica de alimentos. 4. Ed. São Paulo: Varela, 2010.

OLIVEIRA AM, GONÇALVES MO, SHINOHARA NKS, STAMFORD TLM. Manipuladores de alimentos: um fator de risco. Higiene Alimentar, v.17, n.114/115, p. 12 -19, 2003. 
BRASIL. Ministério da Saúde. Agência Nacional de Vigilância Sanitária. Resolução RDC n. 12, de 2 de janeiro de 2001. Regulamento Técnico sobre padrões microbiológicos para alimentos. Brasília; 2001. Diário Oficial da União, Poder Executivo, 10 de janeiro de 2001.

ARÇARI AT et al. Avaliação microbiológica da carne bovina comercializada em cinco supermercados de Vitória, ES. Revista Higiene Alimentar, São Paulo, v. 25, n. 202/203, p.138 144, nov./dez.2011.

AZEVEDO CSC et al. Boas Práticas de Manipulação de Alimentos. Secretaria Municipal de São Paulo, Prefeitura do Município de São Paulo. São Paulo, 2006.

BRASIL. Ministério da Saúde. Agência Nacional de Vigilância Sanitária. Resolução RDC n. 218, de 29 de julho de 2005. Dispõe sobre o Regulamento Técnico de Procedimentos HigiênicoSanitários para Manipulação de Alimentos e Bebidas Preparados com Vegetais. Brasília, Diário Oficial da União, Poder Executivo, 01 de agosto de 2005. 